\title{
From rehabilitation to remission in ankylosing spondylitis
}

\section{Dalla riabilitazione alla remissione nella spondilite anchilosante}

\author{
E. Lubrano ${ }^{1}$, A. Spadaro ${ }^{2}$ \\ ${ }^{1}$ Fondazione Maugeri, IRCCS, Research Institute for Rehabilitative Medicine, Telese Terme; \\ ${ }^{2}$ Chair of Rheumatology, Department of Clinical and Medical Therapy, Sapienza-University of Rome
}

$\mathrm{D}$ uring the past years, exercise and non-steroidal anti-inflammatory drugs (NSAIDs) have been the mainstay of symptom control for Ankylosing Spondylitis (AS), a chronic, inflammatory rheumatic disease characterized by inflammatory back pain due to sacroiliitis and spondylitis.

The ASsessment in AS (ASAS) international working group has constructed evidence based recommendations to guide the physician in the management of AS (1).

Among the major recommendations for the management of AS, the ASAS group stated that there is a level Ib evidence that NSAIDs improve spinal pain, peripheral joint pain, and function, but comparative studies (1) or population-based survey (2) of different NSAIDs/coxib have not demonstrated one preparation to be clearly better than the others. Wanders et al (3) showed that the clinical efficacy of continuous NSAIDs/coxib treatment for AS was similar to intermittent "on demand" use and they suggested that the continuous treatment with NSAIDs/coxib could slow the radiographic disease progression over 2 years. Nevertheless it is premature to conclude that continuous NSAID treatment is disease modifying in AS, because the mean difference in progression of spinal fusion scores between "continuous" and "on demand" groups was small, with a low effect size (0.07) (4).

Other anti-inflammatory options can consider the

Indirizzo per la corrispondenza:

Prof. Antonio Spadaro

Dipartimento di Clinica e Terapia Medica

Divisione di Reumsologia, Sapienza

Università di Roma, Azienda Policlinico Umberto I

Viale del Policlinico, 155 - 00161 Roma

a.spadaro.reuma@virgilio.it use of corticosteroid injections directed to the local site of musculoskeletal inflammation while systemic administration for axial disease is not supported by any evidence (1).

Similarly the efficacy of disease modifying antirheumatic drugs (DMARDs), including sulfasalazine (1) and methotrexate $(1,5,6)$, for the treatment of axial disease is not supported by any evidence. Although the most common sites of inflammation in AS (i.e. sacroiliac joints, entheses, vertebral bodies adjacent to intervertebral discs etc.) are poorly accessible, there is a clear role for TNFalpha in the pathogenesis of AS (7).

Thus patients with persistent high disease activity despite conventional treatments should be treated with anti-TNFalpha treatment according to the ASAS recommendations, but there is no evidence to support the obligatory use of DMARDs before, or concomitant with, anti-TNFalpha treatment in AS patients with axial disease.

The review of clinical data related to adalimumab, etanercept, infliximab compared with conventional treatment plus placebo indicates that the three treatments are clinically effective in relation to assessment of ASAS response criteria, BASDAI and BASFI (8).

Whereas clinical findings demonstrate sustained, durable benefits with long-term therapy in patients with AS, $x$-ray evaluations suggest that progression of structural damage continued. In fact AS patients who received adalimumab (9), etanercept (10) or infliximab (11) did not show a statistically significant difference in inhibition of structural damage progression at year 2, as assessed using the mSASSS scoring system, when compared with radiographic data from the historical control OASIS 
(Outcome in Ankylosing Spondylitis International Study) cohort.

Although the use of anti-TNFalpha treatment in AS patients must be considered a revolution in the treatment strategy of AS, ASAS strengthened that optimal management of AS requires a combination of non-pharmacological and pharmacological treatments. In fact, rehabilitation is still considered one of the main treatments showing, most of the time, some beneficial effects and non-pharmacological therapy (including education, exercise and physiotherapy) was included in the recommendations for the AS management by the ASAS working group/EULAR (1).

Two important issues still to be addressed should be: what type of physical therapy/rehabilitation is the most effective in AS patients, and what is the duration of the positive effects of this treatment, in other words, how long does it last for?

To address the $1^{\text {st }}$ point we can state that physiotherapy interventions for AS have shown to be an important part of the management of the disease, being useful with a tendency to be more effective when done as a supervised outpatient group (1214). The most recent reviews on physiotherapy interventions confirmed this treatment strategy, also indicating that exercise performed by patients under supervision was beneficial on spinal mobility when compared to the home exercise regime, but suggested that further research should be essential to delineate which exercise protocols should be recommended in the management of AS patients (12). Moreover Ton Nghiem et al and Elyan et al in their reviews on the rehabilitation of AS conclude, on the basis of few articles published, that exercise should remain a mainstay of AS treatment complementing medical therapy but there is a need for a standardised approach to assess its real role $(15,16)$.

Recently, a Korean group showed that a homebased daily exercise program increased joint mobility and functional capacity, and decreased pain and depression in AS patients (17). They concluded that home based exercise might be an effective intervention for the disease.

To address the $2^{\text {nd }}$ point, again, there are not clear results. In fact, on the basis of previous studies, various other studies showed that inpatient intensive rehabilitation is effective in inducing short term improvement in spinal mobility (18), but doubts remain about sustained improvement after long periods of time (19-21). In fact, some data showed that patients with AS experienced pro- gressive loss of movement independent to the duration of the disease and the reported frequency of unsupervised exercise (22).

We showed the effectiveness of inpatient rehabilitation assessed by ASAS response criteria and this was quite a novelty using a combined index to measure the real role of rehabilitation (23). Indeed and interestingly, the effectiveness of intensive inpatient rehabilitation declined over time, suggesting that this therapeutic approach, per se, is not enough to control the disease. However, to better measure the effectiveness of rehabilitation, it would be advisable to use the ASAS response criteria in rehabilitation settings.

These contradictory results may depend on methodological differences such as patients' selection and physiotherapy regimen. However, all these results showed, clearly, that any rehabilitation program only plays a partial role in the treatment of the disease and are unable to completely address the management of AS patients. Therefore, the concept of a combination treatment (biologic agents and rehabilitation) has risen in the last few years and, at present, just few papers showed the synergistic effect of biological agents and rehabilitation: in one study, designed by us, Etanercept and an intensive inpatient rehabilitation was used for the management of active AS, and indicating that the combination treatment seemed to be more effective than a simple rehabilitation program (24).

A possible explanation for the good results obtained was that Etanercept, acting on inflammation and fatigue reduction, improved the efficacy of a rehabilitation program, resulting in a better functional status, better quality of life and a better perception of the benefits obtained from the rehabilitation. Similar results were obtained by another study designed by us in which an occupational treatment in combination with biological agents was beneficial with synergistic effects on pain, function and disability when compared to the control groups treated with simple occupational therapy (25). Indeed, this manuscript also showed that an occupational treatment could be effective when associated with powerful biological medications and also it could be used when the disease is stable and well controlled with the drugs, representing a possible tool to maintain and improve the health status of AS patients. Other authors showed that a combination of $\mathrm{TNF} \alpha$ agents and rehabilitation can improve the benefit perceived by the AS patients when doing physiotherapy (26). Therefore, there is a strong body of evidence that anti TNF $\alpha$ agents, as pow- 
erful treatment for AS, can improve the effects of rehabilitation. However, at present, no randomized studies on the combination treatment with any anti TNF $\alpha$ and rehabilitation have been carried out and our previous studies were performed as a pilot study or based on the clinical practice.

Therefore, it would be advisable that to confirm these previous positive results on the combination treatment some randomized studies will be performed to better deal with this fascinating and challenging disease.

\section{REFERENCES}

1. Zochling J, van der Heijde D, Burgos Vargas R, Collantes E, Davis Jr JC, Dijkmans B, et al. ASAS/EULAR recommendations for the management of ankylosing spondylitis. Ann Rheum Dis; 2006; 65: 442-52.

2. Zochling J, Bohl-Buhler MH, Baraliakos X, Feldtkeller E, Braun J. Nonsteroidal anti-inflammatory drug use in ankylosing spondylitis - a population - based survey. Clin Rheumatol 2006; 25: 794-800.

3. Wanders A, Heijde D, Landewé R, Béhier JM, Calin A, Olivieri I, et al. Nonsteroidal antiinflammatory drugs reduce radiographic progression in patients with ankylosing spondylitis: a randomized clinical trial. Arthritis Rheum 2005; 52: 1756-65.

4. Ward MM. Prospects for disease modification in ankylosing spondylitis: do nonsteroidal anti-inflammatory drugs more than treat symptoms? Arthritis Rheum 2005; 52: 1634-6.

5. Chen J, Liu C, Lin J. Methotrexate for ankylosing spondylitis. The Cochrane Database of Systematic Reviewes 2006, Issue 4. Art. No.: CD004524. DOI: 10.1002/14651858.CD004524.pub3.

6. Haibel H, Brandt HC, Song IH, Brandt A, Listing J, Rudwaleit $\mathrm{M}$, et al. No efficacy of subcutaneous methotrexate in active ankylosing spondylitis: a 16-week open-label trial. Ann Rheum Dis 2007; 66: 419-21.

7. Smith JA, Märker-Hermann E, Colbert RA. Pathogenesis of ankylosing spondylitis: current concepts. Best Pract Res Clin Rheumatol 2006; 20: 571-91.

8. Mcleod C, Bagust A, Boland A, Dagenais P, Dickson R, Dundar Y, et al. Adalimumab, etanercept and infliximab for the treatment of ankylosing spondylitis: a systematic review and economic evaluation. Health Technol Assess 2007; 11: 1-158.

9. van der Heijde D, Salonen D, Weissman BN, Landewé R, MaksymowychWP, Kupper H, et al. Assessment of radiographic progression in the spines of patients with ankylosing spondylitis treated with adalimumab for up to 2 years. Arthritis Res Ther 2009; 11: R127.

10. van der Heijde D, Landewé R, Einstein S, Ory P, Vosse $\mathrm{D}, \mathrm{Ni}$ L, et al. Radiographic progression of ankylosing spondylitis after up two years of treatment with etanercpet. Arthritis Rheum 2008; 58: 1324- 31.

11. van der Heijde D, Landewé R, Baraliakos X, Hoube H, van Tubergen A, Williamson $\mathrm{P}$, et al. Radiographic findings following two years of infliximab therapy in patients with ankylosing spondylitis. Arthritis Rheum 2008; 58: 3063-70.

12. Dagfinrud H, Kvien TK, Hagen KB. Physiotherapy interventions for ankylosing spondylitis. The Cochrane Database of Systematic Reviewes 2007, Issue 4. Art. No.: CD002822. DOI: 10.1002/14651858. CD002822.pub2.

13. van der Linden S, van Tubergen A, Hidding A. Physiotherapy in ankylosing spondylitis: what is the evidence? Clin Exp Rheumatol 2002; 20 (6 Suppl 28): S60-4.

14. Analay Y, Ozcan E, Karan A, Diracoglu D, Aydin R. The effectiveness of intensive group exercise on patients with ankylosing spondylitis. Clin Rehabil 2003; 17: 631-6.

15. Nghiem FT, Donohue JP. Rehabilitation in ankylosing spondylitis. Curr Opin Rheumatol 2008; 20: 203-7.

16. Elyan M, Khan MA. Does physical therapy still have a place in the treatment of ankylosing spondylitis? Curr Opin Rheumatol 2008; 20: 282-6.

17. Lim HJ, Moon YI, Lee SM. Effects of home-based daily exercise therapy o joint mobility, daily activity, pain, and depression in patients with ankylosing spondylitis. Rheumatol Int 2005; 25: 225-9.

18. van Tubergen A, Landewe R, van der Heijde D, Hidding A, Wolter N, Asscher M, et al. Combined spa-exercise therapy is effective in patients with ankylosing spondylitis: a randomized controlled trial. Arthritis Rheum 2001; 45: 430-8.

19. Viitanen JV, Suni J, Kautiainen H, Liimatainen M, Takala H. Effect of physiotherapy on spinal mobility in ankylosing spondylitis. Scand J Rheumatol 1992; 21: 38-41.

20. Helliwell PS, Abbot CA, Chamberlain MA. A randomised trial of three different physiotherapy regimes in ankylosing spondylitis. Physiotherapy 1996; 82: 85-90.

21. Kraag G, Stokes B, Groh J, Helewa A, Goldsmith CH. The effects of comprehensive home physiotherapy and supervision on patients with ankylosing spondylitis - an 8-months follow up. J Rheumatol 1994; 21: 261-3.

22. Lubrano E, Helliwell P. Deterioration in anthropometric measures over six years in patients with ankylosing spondylitis. An initial comparison with disease duration and reported exercise frequency. Physiotherapy 1999; 85: $138-43$

23. Lubrano E, D’Angelo S, Parsons WJ, Corbi G, Ferrara N, Rengo F, et al. Effectiveness of rehabilitation in active ankylosing spondylitis assessed by the ASAS response criteria. Rheumatology 2007; 46: 1672-5.

24. Lubrano E, D’Angelo S, Parsons WJ, Serino F, Tanzillo AT, Olivieri I, et al. Effects of a combination treatment of an intensive rehabilitation program and etanercept in patients with ankylosing spondylitis: a pilot study. J Rheumatol 2006; 33: 2029-34.

25. Spadaro A, De Luca T, Massimiani MP, Ceccarelli F, Riccieri, Valesini G. Occupational therapy in ankylosing spondylitis: short term prospective study in patients treated with anti TNF alpha drugs. Joint Bone Spine 2008; 75: 29-33.

26. Dubey SG, Leeder J, Gaffney K. Physical therapy in anti TNF treated patients with ankylosing spondylitis. Rheumatology 2008; 47: 481-3. 